\title{
The Digital Twin is an Artifact of Modern Production Systems
}

\author{
Igor Egorov*, Natalia Polzunova, and Ivan Polzunov \\ Vladimir State University, 600000 Vladimir, Russia
}

\begin{abstract}
The development of modern production systems is taking place in the context of the transition to the concept of Industry 4.0. In these conditions, the competitiveness of production systems is determined by the volume and depth of implementation of digital technologies. These technologies include the digital twin. Recently, a lot of research has been devoted to digital twins. The use of digital twins by modern production systems offers many advantages, both technical and economic. This article provides a systematization of the concept of "digital twin", and also describes the organizational aspects of the development and use of digital twins in production systems designed in the form of a model.
\end{abstract}

\section{Introduction}

In any economy, manufacturing enterprises are key suppliers of new goods, thus their development is considered a central factor in the diversification and massification of demand [1]. Modern production systems must be ready to work in conditions of uncertainty and adapted to solving the tasks assigned to them. All this, as well as the solution of scientific and practical problems in the field of management of modern production systems, require constant development and improvement of the applied methods and approaches, which objectively reflect the current economic dynamics.

Modern trends in the development of society are associated with the ongoing process of globalization, the rapid growth of technologies, breakthroughs in the development of communication structures, including non-hierarchical ones, and serious demographic shifts. All these trends are taking place against the backdrop of widespread information technology and digital transformation.

In the context of the digital transformation of society and the large-scale implementation of the Industry 4.0 concept. information becomes one of the key factors in effective enterprise management. Obtaining timely and timely reliable information about the processes of the enterprise's functioning allows making management decisions that are aimed at increasing the competitiveness and productivity of the business. The core of Industry 4.0. cyber-physical systems and self-optimizing production systems act. New technologies, as well as changes in market requirements, have an impact on the technical and organizational restructuring of production systems on the principles of CEI (Computer Integrated Enterprise), CIM (Computer Integrated Manufacturing), FA (Factory Automation) JIT (Just and in Time). This

\footnotetext{
* Corresponding author: Natalya.polzunowa@yandex.ru
} 
leads to a reduction in costs, a reduction in the production cycle, and an increase in the quality of products [2].

The use of digital technologies in production systems provides a whole range of possibilities. Among these opportunities, the following are significant:

Build and use smarter production processes and monitor them in real time. Creation of feedback loops, contributing, among other things, to adaptive behavior change based on learning.

Increased flexibility, modularity and adaptability of production systems. Application of unmanned and automatic technology in production.

Development and use of effective systems of supply, sales, transport logistics.

Creation and use of a productive and operational system of industrial cooperation.

The development of information technology and the latest advances in this area offer promising opportunities for increasing intellectualization and automation of decision-making [3]. In Russia, by the Decree of the Russian Federation of May 7, 2018 No. 204, the president defined 9 national development goals for the period up to 2024. These goals, among others, include the acceleration of technological development and the acceleration of the introduction of digital technologies.

One of the areas that contributes to the realization of these goals is the creation of digital twins. The digital twin is one of the most promising technologies for implementing smart manufacturing and Industry 4.0 [4].

The digital twin is part of the cyber-physical system [5,6]. The digital twin is a technology integrator of end-to-end digital technologies and acts as a technology driver. It gives a strong impetus for the transition to a new technological order and become a technology leader not only in the local, but also in the global market [7].

The issues of creating digital twins and their introduction into practice were raised in their works by Borovkov A.I., Garanin M.A., Grishina T.G., Komrakov A.R., Solomentsev Yu.A., Storozhuk E.A., Tao F., Zhang M., Grieves M. and many other researchers.

Ongoing research on digital twins focuses on discussions on optimizing the architecture of a digital twin system [8]. There is a certain set of research papers that report on the practice of using digital twins in real systems of different levels and discuss technologies for their implementation.

In this study, an attempt is made to present the organizational aspects of introducing digital twins into the activities of modern production systems.

\section{Materials and Methods}

The presented research was carried out in accordance with the following stages:

To conduct a bibliometric analysis of the use of the concept of "digital twin"

To propose a model describing the process of creating and implementing digital twins.

To solve these problems, a systematic approach was used, as well as some scientific methods, such as abstract logical, theoretical search, methods of comparative and bibliometric analysis, modeling.

The initial data for obtaining the results were taken from conference materials, analytical reports, scientific reports. We used marketing research data, as well as articles indexed in the Scopus, Web of Science, Elibrary databases.

The expert community was involved to verify the constructed model. 


\section{Results and Discussion}

Recently, a lot of studies have been devoted to the study of digital twins. The frequency of using the term "digital twin" in different bibliographic databases is shown in Fig. 1. It should be borne in mind that there is some lag between publication and its appearance in the library or search engine, so the number of publications in 2019 will eventually increase. The data presented indicate an explosive interest in this topic. The graph shows the search data for the query "digital twin", limited by keywords, title and annotations. If we expand the search framework by mentioning this term in the text of publications, then their number will increase significantly.

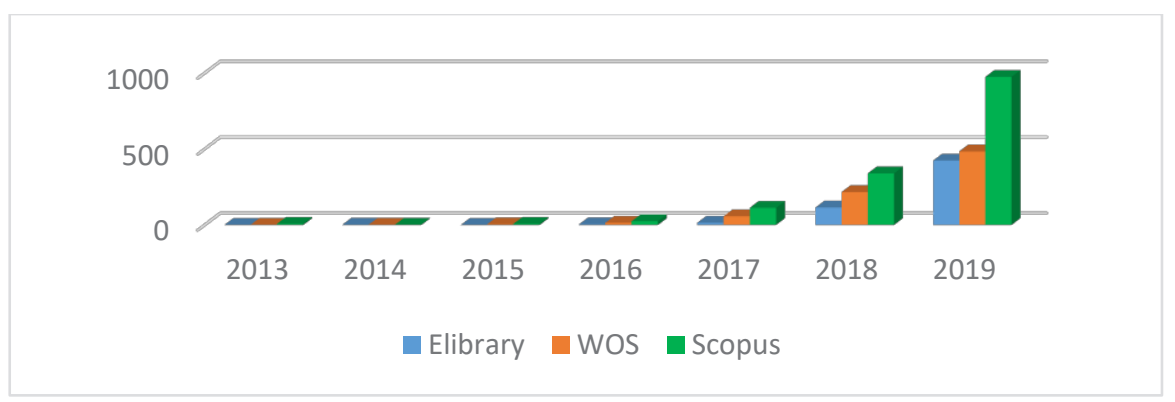

Fig. 1. Dynamics of publications on the topic of "digital twins"

The main publications are presented in the category of technical sciences and information support. Research in the field of economics and management began to appear, to a greater extent they are associated with the organizational support for the development and implementation of digital twins in production. Here are the statistics of publications on the topic of digital twins in the context of thematic areas in the WOS database (Fig. 2). Only 18 articles were published in the direction of "Management".

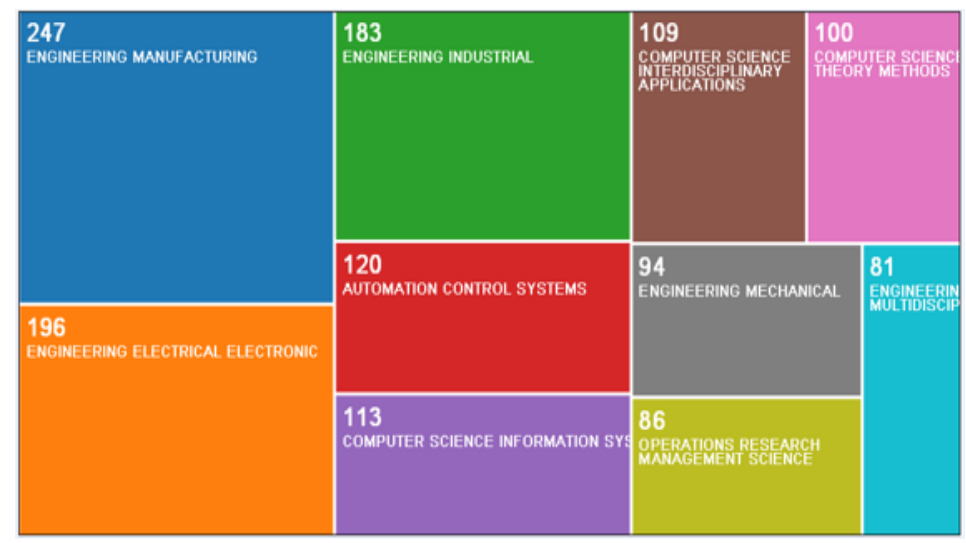

Fig. 2. Distribution of $80 \%$ of publications from "Digital Twin" queries by industry direction in WoS

Today, not only research is carried out and its results are published on the topic of "digital twins", but these technologies are actively entering the main use. A survey of heads of organizations showed that $13 \%$ of organizations implementing IoT projects are already using digital twins, and $62 \%$ are either in the process of creating digital twins or planning to do so [9]. 
Gartner predicts that by 2021, half of all large industrial companies will use digital twins, as a result of which the efficiency of these organizations will increase by at least $10 \%$. And Deloitte predicts that the global digital twin market will reach $\$ 16$ billion by 2023 [10] and by $2025-\$ 32.36$ billion [11].

The digital twin market is expected to grow at a CAGR of $38 \%$ [12].

Such a massive use of the term requires a certain systematization of it. Here is the classification (Fig. 3). The most commonly used division of digital twins by essence. It should be noted that the types of digital twins, according to this criterion, do not replace each other, but complement each other, working to achieve the common goals of enterprises. Features of the types of digital twins by the criterion "essence" are given in Table 1.
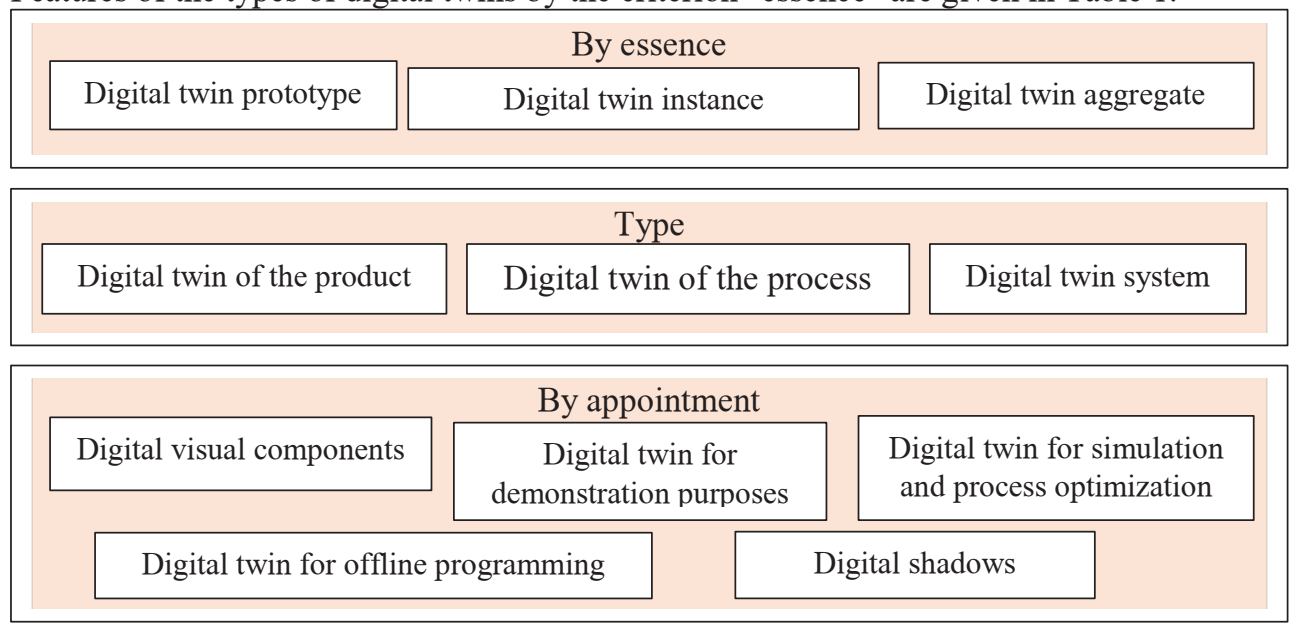

Fig. 3. Classification of digital twins [13]

Table 1. Distinctive features of digital twins

\begin{tabular}{|c|c|c|c|}
\hline $\begin{array}{c}\text { Comparison } \\
\text { parameter }\end{array}$ & Digital twin prototype & Digital twin instance & $\begin{array}{l}\text { Digital twin } \\
\text { aggregate }\end{array}$ \\
\hline describes & $\begin{array}{l}\text { Some dynamic functions of } \\
\text { a specific object }\end{array}$ & $\begin{array}{l}\text { A specific physical product at } \\
\text { different stages of the life cycle }\end{array}$ & $\begin{array}{l}\text { A collection, many } \\
\text { specific physical } \\
\text { objects }\end{array}$ \\
\hline includes & $\begin{array}{l}\text { 3D model, cost, design } \\
\text { model, bill of materials, } \\
\text { processes, product } \\
\text { requirements }\end{array}$ & $\begin{array}{l}\text { 3D model, cost, process model } \\
\text { of object creation, operational } \\
\text { model / operating states } \\
\text { obtained using sensors }\end{array}$ & All virtual instances \\
\hline applied & Early in the life cycle & At all stages of the life cycle & $\begin{array}{l}\text { At all stages of the } \\
\text { life cycle }\end{array}$ \\
\hline $\begin{array}{l}\text { tasks to be } \\
\text { solved }\end{array}$ & $\begin{array}{l}\text { Test different hypotheses, } \\
\text { evaluate different work } \\
\text { scenarios }\end{array}$ & Predict the state of a real object & $\begin{array}{l}\text { Describe the group } \\
\text { behavior of real } \\
\text { objects }\end{array}$ \\
\hline
\end{tabular}

Digital shadows are a kind of digital twins [13]. Their task is to receive digital information in real time from equipment control systems or technical devices. As noted, $90 \%$ of the information obtained in this way is "junk" information [14]. The digital twins in the operational phase are essentially digital shadows.

The introduction of digitalization tools into the activities of modern production systems entails an increase in the efficiency of their functioning [15]. The digital twin introduced into practice will allow solving a whole set of tasks. Embedding digital twins in a production system is a complex task that requires organizational effort, the availability of the appropriate infrastructure and technical readiness. In Fig. 4, we present an organizational model for the development and use of digital twins in a modern production system. The presented model 
describes a sequential process, where three stages are distinguished: the preparatory stage, directly, the stage of creating a digital twin, the stage of introducing digital twins into the production system.

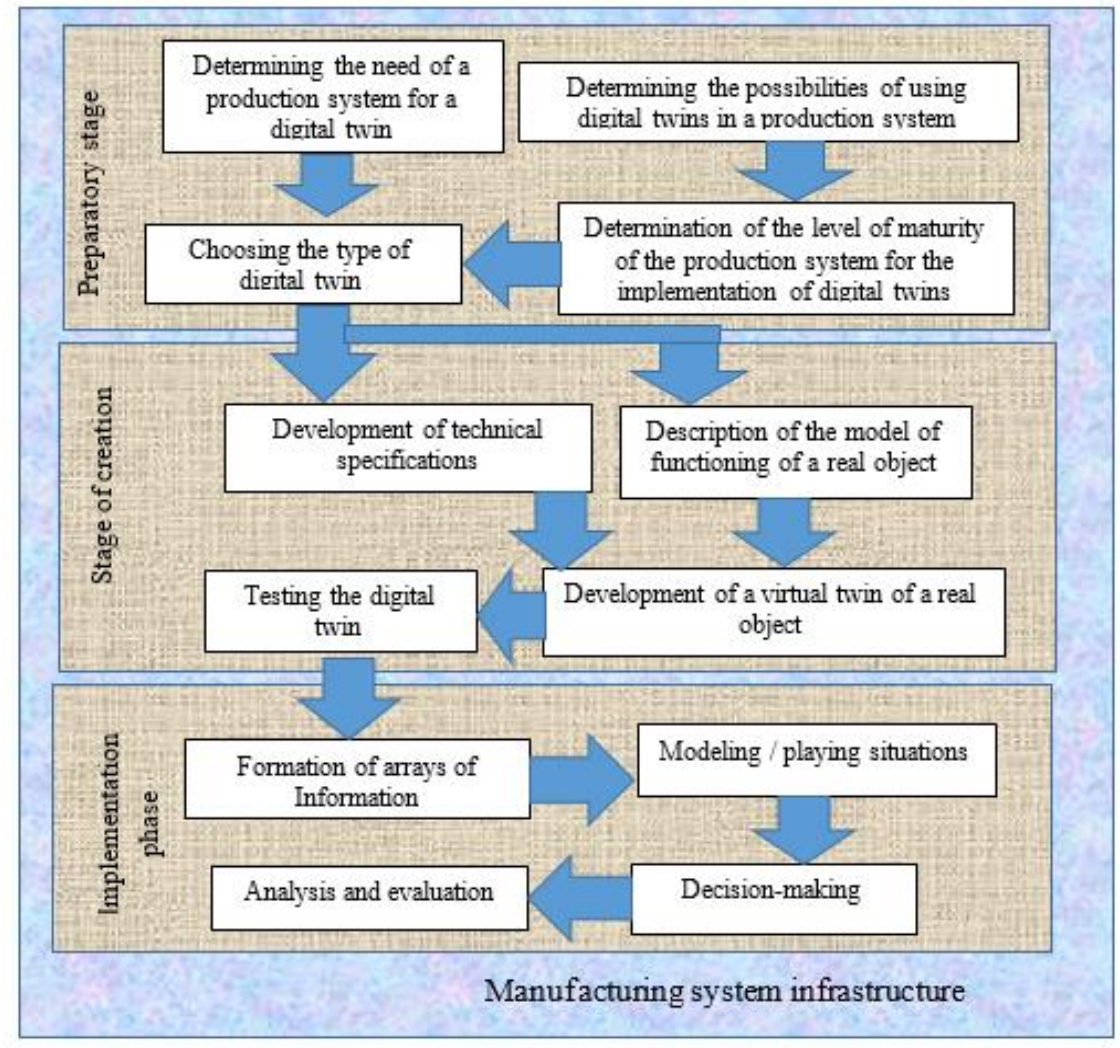

Fig. 4. Stages of work on the implementation of a digital twin in the production system

The final process during the implementation phase is the analysis and evaluation. In addition to identifying problems, the effectiveness of the implementation of digital twins is assessed. Such an assessment implies the calculation of technological, social, environmental and economic effects, as well as the comparison of the results obtained with the costs.

At each of the stages presented, control is carried out. The control system of each stage, like any control system, consists of elements. These elements include: goals and objectives of management, organizational and information support, subject and object of management. The control system for the implementation of digital twins is presented in Fig. 5. It is part of the overall management system of the production system. The purpose of management is to improve the efficiency and productivity of the production system. 


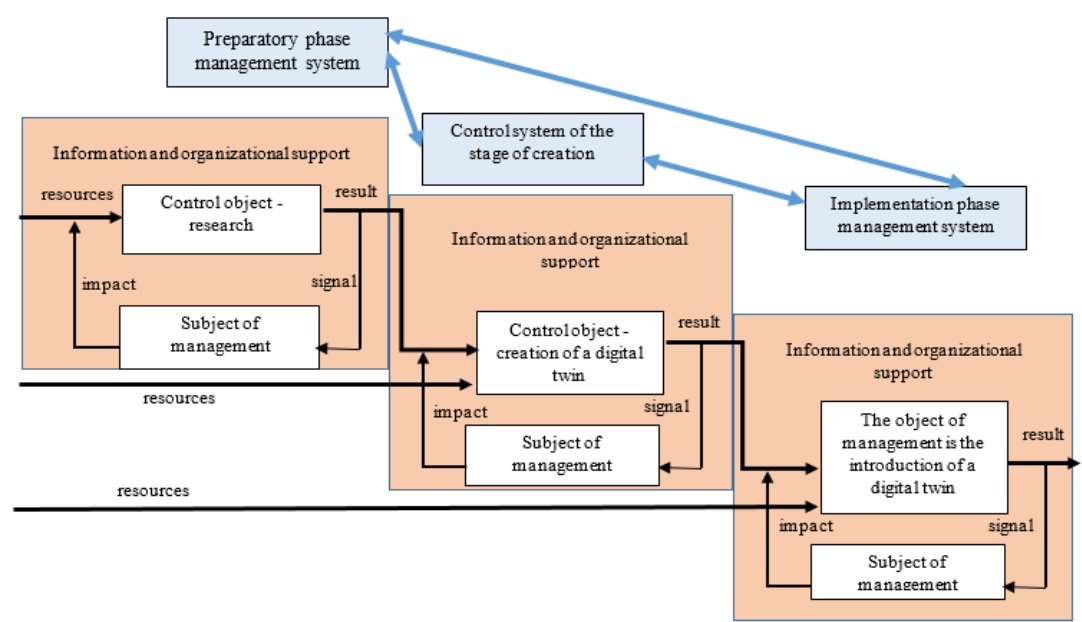

Fig. 5. Management system for the creation and implementation of digital twins

Only a well-built management system for all stages, both by the system and by each stage separately, will allow achieving the intended results.

\section{Conclusions}

Mass digitalization creates new requirements and presents new opportunities to ensure competitive advantage. Digital transformation implies the need for a transition to the widespread introduction of digital twins in production systems. The integration of digital twins into production processes will increase the efficiency of the functioning of production systems and increase their competitiveness.

Our research complements other research on digital twins and their use in manufacturing systems. We present a model for the creation and implementation of digital twins in modern production systems, which consists of three sequential stages: the preparatory stage, the creation stage and the implementation stage.

Further research direction requires the development of methods for assessing the level of maturity of production systems for the implementation of digital twins.

The results obtained can be used to build an organizational and economic mechanism for managing digital twins in modern production systems, in the formation of a strategy to ensure the competitiveness of production systems.

\section{References}

1. Industrial Development Report. Demand for Manufacturing: Driving Inclusive and Sustainable Industrial Development, Overview (2018)

2. A. Aleksakhin, E. Eliseeva, I. Zaytsev, Y.Aleksakhina, L. Kostygova, MATEC Web of Conferences, EDP Sciences (2019)

3. F. Ameri, R. Sabbagh, International Conference on Advances in Production Management Systems, (2016)

4. F. Tao, H. Zhang, A. Liu, Transactions on Industrial Informatics, 15(4) (2018)

5. G. N. Schroeder, C. Steinmetz, C. E. Pereira, D. B. Espindola, IFAC-Papers OnLine, 49 (2016) 
6. K. M. Alam, A. El Saddik, IEEE Access, 5 (2017)

7. Roadmap for development of “cross-cutting” digital technology "New production technologies" (2019)

8. G. Zhao, X. Cao, W. Xiao, Y. Zhu, K. Cheng, In Proceedings 4th International Conference on Automation, Control and Robotics Engineerin (2019)

9. K. Costello, G. Omale, Gartner Inc. Retrieved, April 30 (2019)

10. Why do we need digital counterparts in the chemical industry? https://sber.pro/

11. Global Digital Twin Market, Market Research Report (2019)

12. V. Raghunathan, April 16 (2019) https://www.entrepreneur.com/

13. S. Kuznetsova, Problems of economics, finance and production management, 45 (2019)

14. Digital Twins counterparts in the high-tech industry, TechNet (2019)

15. N. Polzunova, I. Savelyev, I. Polzunov, O. Ruzevich, Industry Competitiveness: Digitalization, Management, and Integration, 2 (2021) 